\title{
Rail, Rivers, Road or Air: Which infrastructure promotes growth in China?
}

\author{
Jack Strauss, Hongchang Li, Kemei Yu, Xinyu Wang \\ Jack.Strauss@du.edu
}

\begin{abstract}
We examine the relationship between growth in transportation and economic output across Chinese provinces from 2005-2014. Panel GMM methods evaluate the impact of changes in air, conventional rail, HSR, roads, and waterways turnover volume on provincial output growth. GMM estimates demonstrate that rail and roads significantly affect economic growth; rail's impact is particularly significant and its estimates are economically large for agriculture and manufacturing output. In contrast, air, HSR and water usage do not contribute to economic growth. Impulse responses indicate that rail and roads considerably affect GDP growth across China, and there is bi-causality between transportation and economic growth. Cost-benefit analysis highlights that the benefit of roads, and particularly rail, outweigh the costs of infrastructure spending.
\end{abstract}

\section{Introduction}

China's investment in infrastructure has skyrocketed more than five times over the past ten years. A decade ago, China spent $40 \%$ of the combined G7 infrastructure spending on roads, rail and air; however, by 2016, China's infrastructure budget was 2.5 times the G7 (OECD, 2016). Has this remarkable boost in fixed investment of transportation produced increases in freight and passengers that have contributed to economic growth in China? High-speed rail (HSR) particularly has been prioritized; it began full-scale operation in 2008 and by 2015, China had more tracks than the rest of the world combined. The rapid buildup of Chinese HSR began in 2008 when China laid out the blueprint for building 4-vertical and 4-horizontal corridors. A decade later, the network extended to 29 Chinese provinces and reached 26,000 km, accounting for two-thirds of global HSR tracks. By 2020, 192 prefecture-level Chinese cities will be connected by 30,000 HSR tracks for a cost of 3.5 trillion RMB; by 2025 , a new $8 \times 8$ rail network will comprise nearly $40,000 \mathrm{~km}$ of track and cover most major Chinese cities (UIC, 2018; Lu, 2018).

Over the past twenty-five years, China has also invested heavily in air infrastructure. The number of civil airports in China increased from 94 in 1990 to 175 in 2010 and reached 229 by 2017. In 2016, the government announced plans 
to invest 77 billion yuan annually to promote air infrastructure that will boost the number of airports to 272 within five years; the investment will support eleven large infrastructure projects and 52 extensive upgrades on civil aviation facilities (Liu, 2016). In contrast, the last major U.S. airport was built more than two decades ago in Denver, and there are no new airports on the drawing board (Modak, 2017). Has the government's fixed investment in HSR and air, nontraditional infrastructure investment, contributed to China's rapid economic growth?

The case for infrastructure spending for promoting economic activity is well documented in the literature but has received recent scrutiny due to high costs. While some research supports a positive diffusion effect through more spatially balanced economic development and employment distribution (Sasaki, 1997), agglomeration effects also are espoused by geographical economists (e.g., Fujita et al., 1999). In contrast, Ansar et al. (2016) show that China's infrastructure record has failed to boost economic growth beyond the construction phase. The rapid buildup of HSR and airports has renewed the issue of possible government misallocation in China. China's Railway's total debt stands at five trillion (RMB), and 80 percent of the debt is related to HSR. Mitchell \& Liu (2018) report that the HSR network is a debt crisis waiting to happen; the network is dependent on unsustainable government subsidies with many rail lines unable to repay the interest on the debt, let alone its principal. Airport investment may also be overbuilt; of 183 airports in operation across the country, 134 were deficit-ridden facilities of branch airlines with losses totaling 2.9 billion yuan or US\$474.15 million (China.org, 2014). By 2017, China has too many airports with few passengers as three-quarters of its 200-plus airports are unprofitable. (Huifeng, 2017).

Banerjee et al. (2012) argue that a key component in evaluating infrastructure's effects on economic growth is appropriately modeling causality; for instance, although rich economies have dramatically better transport networks than poorer economies, market forces may have naturally provided the impetus for the investment. A second concern is whether the government selects the appropriate infrastructure to promote. Seminal work by Fogel (1962) shows that although rail was often cited as an essential tool of government in promoting economic growth in the $1800 \mathrm{~s}$, it was an example of government misallocation, since it was less effective in enhancing economic growth than pre-existing river networks.

Tong and Yu (2018, page 120) report that despite both sizeable political support and financial investment in transportation network, "little is understood regarding the relationship between transportation and regional economic growth in China." They survey the literature on China's transportation infrastructure and find few empirical studies that examined the interaction between China's transportation network and regional economic growth; they conclude that clear consensus exists regarding this interaction.

This paper marks progress in evaluating the interrelationships between different modes of infrastructure and regional economic growth in China. Our panel dataset 276 
from 2005-2014 consists of the 31 province-level divisions in China, and includes provincial data on air, conventional rail, HSR, roads, waterways, and economic output. We accommodate for transportation's potentially sizeable feedback effects and endogeneity with dynamic GMM and VAR methods. Our paper is the first in China to estimate multiple transportations modes and their impact on primary (agriculture), secondary (manufacturing) and tertiary (service) GDP; Lastly, we examine the cost of infrastructure spending compared to the benefits of higher economic growth.

A preview of our results demonstrates that increases in rail and road turnover volume have a significant impact on economic growth in China. GMM parameter estimates indicate that a $1 \%$ increase in rail and road turnover volume (or usage) leads to respective boosts of $.11 \%$ and $.07 \%$ in regional output growth. Rail and road's positive effects are significant and economically large for agriculture and manufacturing output growth, and significant with smaller coefficient estimates for service output. Rail has a strong impact on all three regions of China, while roads are also significant. Changes in air, HSR and water infrastructure have little effect on GDP growth and their impacts are not robust across specifications.

Lastly, a cost- benefit analysis determines that the economic benefit of roads, and particularly rail, outweigh their costs. In contrast, the growing costs of HSR with little economic benefit may lead to debt challenges for China' Rail Corporation that has to pay the interest payments on the infrastructure construction.

\section{Background}

Transportation's affirmative effect on infrastructure was laid out by prominent work by Aschauer (1989) and Munnell (1990). Research by Chatman and Noland (2011) shows that reducing transport costs and increasing accessibility leads to positive agglomeration effects. HSR's impact on the Chinese economy has recently emerged as a hot topic for both academic and policy-related reasons. The rapid implementation of HSR was part of a hefty four trillion yuan infrastructure investment plan to mitigate the effects of the global financial crisis. Its goal was to boost accessibility as well as modernize the network capacity for passengers and freight, rebalance network inequalities and foster rail innovation (Chen \& Vickerman, 2016). Li et. al (2018) show that China's HSR leads to economic growth. However, Wu et al. (2014) shows that HSR may not be worth the cost relative to conventional rail.

The argument for government subsidies for HSR relies on the simple intuition that fast rail can better connect consumers, businesses and ideas together. Before intercity competition can generate economic activity, there must be reliable physical market access; e.g., a generation ago, China consisted of dozens of isolated pockets of large cities with many millions of consumers, but with few quick transport connections between cities. Transportation infrastructure such as HSR increases 
the access of medium cities, large cities and megacities to each other, and due to agglomeration effects of cities, may lead capital and skilled labor to move to regions that are more productive.

\section{Model and Estimation Methods}

Transportation infrastructure is an important factor affecting economic growth. According to an extended Cobb-Douglas production function (Su \& Zhao, 2011), traffic infrastructure can be introduced as a factor that affects technological progress. As a result, we estimate:

$$
G D P_{i t}=c_{i t}+\gamma_{1} \text { Rail }_{i t}+\gamma_{2} \text { Road }_{i t}+\gamma_{3} \text { Water }_{i t}+\gamma_{4} \text { HSR }_{i t}+\beta_{1} K_{i t}+\beta_{2} H C_{i t}+\varepsilon_{i t}
$$

To induce stationarity and avoid spurious inferences, we difference the data, and hence examine changes in real output for each province. To study the effects of transport infrastructure on economic growth, we use converted turnover volume to measure the level of transport infrastructure of conventional railways, highways, waterways and HSR in different regions. For air, we combine the log of air freight tons and the log of passenger volume; alternative specification of this variable had little effect on inference. The data of GDP, passenger volume, freight volume, and passenger turnover of all modes of transportation except HSR are all from China Statistical Yearbook. Rail data are from the website of the State Railway Administration. The data consist of all 31 Chinese province-level divisions from 2005-2014.

\section{Results}

Table 1 presents aggregate fixed investment expenditures since 2003. Column one shows that total fixed transportation investment rose sharply from 548 billion yuan in 2003 to 52939 billion yuan in 2017, reflecting annual increases of nearly $19 \%$. Roads receive more than half the total infrastructure investment budget. Rail is the next most important transportation investment budgetary item and receives roughly $25 \%$ of the budget; HSR receives $42-77 \%$ of the annual total rail budget and less than $10 \%$ of the overall transportation budget. Air and water infrastructure each receive about $3-4 \%$ of the transportation budget. For comparison, the last two columns present fixed investment for education and health care. Most of the spending in these categories for education and health are likely operating expenses including wages, and not in new buildings or facilities (investment), which is the spending we report here. Nonetheless, the building of roads in China exceeds the building of schools and other educational facilities by a factor of nearly four and exceeds construction of hospitals and other healthcare facilities by a factor of over seven times. 
Table 1. Annual fixed investment in infrastructure

\begin{tabular}{|l|l|l|l|l|l|l|l|l|l|}
\hline & $\begin{array}{l}\text { Total } \\
\text { Trans }\end{array}$ & Roads & $\begin{array}{l}\text { Total } \\
\text { Rail }\end{array}$ & HSR & $\begin{array}{l}\text { Conv. } \\
\text { Rail }\end{array}$ & Water & Air & Educ & Health \\
\hline 2003 & 548 & 361 & 71 & & & 36 & 22 & 147 & 33 \\
\hline 2004 & 682 & 467 & 85 & & & 54 & 27 & 180 & 42 \\
\hline 2005 & 854 & 558 & 127 & & & 78 & 30 & 197 & 55 \\
\hline 2006 & 1078 & 648 & 197 & & & 100 & 46 & 213 & 65 \\
\hline 2007 & 1228 & 693 & 249 & 60 & 189 & 111 & 61 & 222 & 73 \\
\hline 2008 & 1469 & 741 & 407 & 224 & 193 & 120 & 59 & 236 & 94 \\
\hline 2009 & 2160 & 1056 & 666 & 425 & 241 & 167 & 61 & 324 & 145 \\
\hline 2010 & 2462 & 1228 & 744 & 569 & 176 & 194 & 83 & 372 & 155 \\
\hline 2011 & 2713 & 1608 & 592 & 428 & 164 & 193 & 84 & 389 & 191 \\
\hline 2012 & 2990 & 1747 & 613 & 421 & 192 & 201 & 112 & 461 & 220 \\
\hline 2013 & 3451 & 2050 & 669 & 309 & 360 & 212 & 131 & 540 & 259 \\
\hline 2014 & 4046 & 2451 & 768 & 355 & 413 & 244 & 143 & 671 & 320 \\
\hline 2015 & 4473 & 2861 & 773 & 357 & 416 & 235 & 184 & 772 & 394 \\
\hline 2016 & 4937 & 3294 & 775 & 328 & 446 & 216 & 222 & 932 & 460 \\
\hline 2017 & 5701 & 4030 & 801 & 339 & 461 & 189 & 240 & 1108 & 524 \\
\hline Annual & $18.6 \%$ & $19.2 \%$ & $21.5 \%$ & $35.4 \%$ & $12.8 \%$ & $13.9 \%$ & $19.6 \%$ & $15.8 \%$ & $22.2 \%$ \\
\hline
\end{tabular}

(billion RMB)

Data are from the Chinese Statistics yearbook. Total Trans (transportation) includes road, rail, water, air, pipeline and urban transport; urban public is missing for several years but extrapolated. The last row is the average annual growth rate. HSR and conventional (Conv.) rail budget division in 2007 and 2008 are estimated. Educ (Education) and Health investment are also presented for comparison.

Table 2 presents summary statistics for the data. The first row reports average annual growth rates; real GDP grew by $7.4 \%$, while road and conventional rail grew by $19.5 \%$ and $6.9 \%$ respectively. HSR volumes increases averaged $50 \%$ as it was nonexistent until 2008. Human capital grew the slowest, as Chinese modest population growth implies years of education can only rise slowly over-time. Autocorrelations in the second row show most exhibit modest autocorrelation.

Table 2. Summary Statistics

\begin{tabular}{|l|l|l|l|l|l|l|l|l|}
\hline & GDP & K & HC & Road & Rail & HSR & Water & Air \\
\hline Mean & 0.074 & 0.154 & 0.016 & 0.195 & 0.069 & 0.519 & 0.053 & 0.136 \\
\hline Autocorr & 0.274 & 0.862 & -0.271 & -0.062 & 0.361 & -0.089 & 0.051 & -0.382 \\
\hline
\end{tabular}


Table 2 presents the mean growth rates for all variables in the first row, and autocorrelations (Autocorr) in the second row. RGDP is real GDP growth, $\mathrm{K}$ and HC are the growth rates for physical and human capital respectively. Road, Rail, HSR, Water and air are the growth of turnover for roads, conventional rail, HSR, water and air, respectively.

Table 3 presents GMM estimation results that handles endogeneity (see Arellano and Bover (1995); we report robust standard errors in parentheses. Column I present GMM estimates using lagged orthogonal Deviations (Arellano \& Bover, $1995)$ that remove individual effects; the procedure applies the AB-n step, which uses residuals from the first step. Results show that human and physical capital are strong determinants of GDP. Rail, roads and water and also significantly related to GDP. A $1 \%$ increase in rail (road) growth is associated with a .11\% $(.07 \%)$ increase in regional economic output.

Table 3. GMM estimates of GDP 2005-2014

\begin{tabular}{|c|c|c|c|c|c|c|c|c|c|}
\hline & $\begin{array}{c}\text { I } \\
\text { GDP }\end{array}$ & $\begin{array}{c}\text { II } \\
\text { GDP }\end{array}$ & $\begin{array}{c}\text { III } \\
\text { GDP }\end{array}$ & $\begin{array}{c}\text { IV } \\
\text { Com }\end{array}$ & $\begin{array}{c}\mathrm{V} \\
\text { Fixed }\end{array}$ & $\begin{array}{c}\text { VI } \\
\text { GMML2 }\end{array}$ & $\begin{array}{c}\text { VII } \\
2005-12\end{array}$ & $\begin{array}{c}\text { VIII } \\
2007-14\end{array}$ & $\begin{array}{c}\text { IX } \\
\text { OLSF }\end{array}$ \\
\hline \multirow[t]{2}{*}{$\mathrm{HC}$} & $22.64^{* * *}$ & $24.67^{* * *}$ & $24.84^{* * *}$ & $16.30^{* *}$ & $39.50^{* * *}$ & $20.78^{* * *}$ & $19.57^{* *}$ & $25.35^{* * *}$ & $24.605^{* *}$ \\
\hline & $(4.57)$ & $(5.79)$ & $(4.04)$ & (7.70) & (11.62) & $(6.64)$ & $(8.58)$ & $(9.07)$ & $(5.52)$ \\
\hline \multirow[t]{2}{*}{ K } & $57.19^{* * *}$ & $43.25^{* * *}$ & $54.79^{* * *}$ & $28.17^{* * *}$ & 19.02 & $56.11^{* *}$ & $21.88^{* * *}$ & $44.51^{* * *}$ & $45.00^{* * *}$ \\
\hline & $(7.92)$ & $(12.80)$ & $(6.29)$ & $(10.87)$ & (13.39) & (21.33) & $(6.00)$ & $(7.67)$ & $(6.69)$ \\
\hline \multirow[t]{2}{*}{ Rail } & $10.71^{* * *}$ & $9.16^{* * *}$ & $17.91^{* * *}$ & $24.02^{* * *}$ & $65.82^{* * *}$ & $14.13^{* * *}$ & $7.77^{* * *}$ & $8.15^{* * *}$ & $15.49^{* * *}$ \\
\hline & (1.63) & (1.31) & (3.63) & $(8.37)$ & (12.24) & $(3.23)$ & $(2.21)$ & $(2.11)$ & $(4.32)$ \\
\hline \multirow[t]{2}{*}{ HSR } & -0.30 & -0.45 & -0.04 & 1.03 & 0.57 & -0.08 & -0.31 & -0.91 & -0.15 \\
\hline & $(0.27)$ & $(0.28)$ & $(0.27)$ & $(0.64)$ & $(0.38)$ & $(0.30)$ & $(0.35)$ & (0.49) & $(0.23)$ \\
\hline \multirow[t]{2}{*}{ Road } & $7.22^{* * *}$ & $6.23^{* * *}$ & $6.43^{* * *}$ & $22.46^{* * *}$ & $7.41^{* * *}$ & $6.38^{* * *}$ & $4.60^{* * *}$ & $6.36^{* * *}$ & $5.59^{* * *}$ \\
\hline & $(0.41)$ & $(0.34)$ & $(0.62)$ & (4.59) & (1.84) & $(0.53)$ & $(0.42)$ & $(0.63)$ & $(0.89)$ \\
\hline \multirow[t]{2}{*}{ Water } & $1.32^{* * *}$ & 1.29 & -0.32 & 3.38 & -3.64 & $2.30^{* *}$ & $1.10^{* *}$ & $1.30^{* * *}$ & -0.46 \\
\hline & $(0.42)$ & (1.24) & $(0.24)$ & (4.71) & $(6.32)$ & $(0.98)$ & $(0.44)$ & $(0.47)$ & $(0.96)$ \\
\hline \multirow[t]{2}{*}{ Air } & 1.61 & 1.41 & $2.42^{* * *}$ & -1.68 & 2.04 & 1.91 & 1.55 & 1.60 & 1.67 \\
\hline & (1.35) & (1.59) & $(0.55)$ & $(4.62)$ & (1.99) & (1.46) & (0.95) & (1.33) & $(1.51)$ \\
\hline \multirow[t]{2}{*}{ Labor } & & & -7.40 & & & & & & \\
\hline & & & $(-6.55)$ & & & & & & \\
\hline SE & 0.06 & 0.06 & 0.06 & 0.07 & 0.06 & 0.09 & 0.04 & 0.05 & 0.04 \\
\hline J statistic & 30.32 & 15.94 & 29.47 & 13.22 & 24.62 & 29.72 & 31.0 & 27.07 & .323 \\
\hline J Prob. & 0.17 & 0.90 & 0.17 & 0.10 & 0.48 & 0.19 & 0.18 & .30 & \\
\hline
\end{tabular}


Column I estimates GDP growth using Arellano and Bond's (AB) n-step orthogonal GMM specification with dynamic lags. II presents estimates with traditional differences and $A B-1$ step. Columns III adds labor to the $A B-n$ step orthogonal procedure. IV and $V$ uses GMM with common and fixed effects. VI uses the $A B-n$ step differenced procedure with 2 lags. VII (VIII) uses AB-n step with orthogonal differences for the sample period 2005-2012 (2007-2014). IX presents OLS estimates with fixed effects, and the number for the $\mathrm{J}$ statistic is the adjusted $\mathrm{R}^{2}$ statistic. All variables are in growth rates. All equations report robust standard errors in parentheses. Coefficient estimates and standard errors are multiplied by 100 for presentation, and hence a $1 \%$ increase in human capital for instance leads to a $.22 \%$ increase in real GDP. ${ }^{* * *},{ }^{* *}$ and ${ }^{*}$ are $1 \%, 5 \%$ and $10 \%$ significance.

The remaining columns assess the robustness of alternative specifications. Results that difference the data to remove individual effects (e. g., traditional, nonorgonalized differences) and apply an $A B$ one-step procedure (instead of $A B-n$ ). Column III uses the same specification as I but adds labor; the variable is insignificant and dropped from additional specifications. Column IV (V) present GMM estimates using a common (fixed) intercept. Rail and road estimates are significant and large; water coefficients are not robust to these specifications. Column VI uses an additional lag of all variables, and results are similar to $\mathrm{I}$.

VII (VIII) estimates the GMM specification in column I but over the time period 2005-2012 (2007-2014). Although approximately half the data are different between these two time-periods, inspection between these columns reveals relatively similar rail and road estimates. The robustness of the coefficient estimates suggests relatively stable parameter estimates over-time; further, note, the rail and road estimates are slightly larger for the later time-period, this suggests these variables have not hit diminishing returns. Since transportation spending and turnover have increased over-time, diminishing returns implies the parameter estimates would decline over time. Lastly, an OLS specification with fixed effects in IX shows relatively similar and significant estimates for $\mathrm{HC}, \mathrm{K}$, rail and roads, although these parameter estimates are likely biased.

Overall, railroad and road are significant in all specifications and average across the eight GMM specifications 19.19 and 8.38, respectively. Water (air) average .84 (1.3) and are significant in only three (one) GMM specifications. HSR is not significant in any GMM specification. The control variables, human and physical capital, are significant in nearly all GMM specifications.

An alternative method to accommodate for endogeneity is vector autoregressions and impulse response functions. A vector autoregression uses only lags and is often used in policy analysis by central banks to study multiple variables with endogenous interactions. For instance, prominent work by Bernanke et al. (2005) construct a VAR to trace out the effects of monetary innovations on the economy. Impulse response functions evaluate the impact of a shock in one variable on another. In our case, we plot the relationship between changes in transportation variables and 
real GDP. To highlight and isolate the importance of transportation and reduce the dimensionality of the matrix, we do not include human and physical capital. We plot generalized impulse response functions as the method's output is invariant to ordering.

Figure I highlights a significant positive response of GDP growth to innovations in past rail and road turnover-volume growth. In contrast, innovations to water, air and HSR have no impact on real GDP growth. Figure II highlights the importance of endogeneity and bi-causality, a topic we revisit in the next section. Increases in GDP lead to higher turnover volume of rail and roads.

Table 4 presents Granger Causality statistics. The $\mathrm{c} 2$ statistic and probability are presented. Panel A represents the specification that growth in transportation turnover do not Granger Cause GDP growth; rejection (high c2 statistics and low probability) implies that transportation 'Granger Causes' or contributes/examines future GDP growth. Panel B represents the specification that GDP does not Granger Causes growth in transportation; rejection implies that GDP growth leads to more transportation turnover in the future. Results clearly document bi-causality between transportation and GDP; thus, confirming the importance of modeling the endogeneity through GMM and VAR methods.

Table 4. Granger Causality

Growth in Transportation does not Granger cause GDP growth

\begin{tabular}{|l|l|l|l|l|l|l|l|}
\hline Panel A & HSR & AIR & WATER & ROAD & RAIL & HC & K \\
\hline GDP & 10.90 & 6.18 & 13.71 & 64.37 & 9.99 & 24.44 & 32.51 \\
\hline & 0.03 & 0.19 & 0.01 & 0.00 & 0.04 & 0.00 & 0.00 \\
\hline GDP1 & 13.64 & 4.16 & 21.90 & 17.61 & 2.01 & 4.11 & 14.91 \\
\hline & 0.01 & 0.39 & 0.00 & 0.00 & 0.73 & 0.39 & 0.00 \\
\hline GDP2 & 9.69 & 6.65 & 11.62 & 53.57 & 8.44 & 17.80 & 23.61 \\
\hline & 0.05 & 0.16 & 0.02 & 0.00 & 0.08 & 0.00 & 0.00 \\
\hline GDP3 & 1.25 & 2.88 & 8.80 & 20.90 & 1.71 & 36.47 & 26.10 \\
\hline & 0.87 & 0.58 & 0.32 & 0.02 & 0.79 & 0.00 & 0.01 \\
\hline
\end{tabular}

\begin{tabular}{|l|l|l|l|l|l|l|l|}
\hline Panel B & Growth in GDP does not Granger Cause Transportation \\
\hline GDP & 2.93 & 1.21 & 0.81 & 10.75 & 14.77 & 26.38 & 12.17 \\
\hline & 0.57 & 0.88 & 0.94 & 0.03 & 0.01 & 0.00 & 0.02 \\
\hline GDP1 & 8.10 & 4.40 & 0.75 & 4.02 & 5.82 & 17.62 & 4.95 \\
\hline & 0.09 & 0.35 & 0.95 & 0.40 & 0.21 & 0.00 & 0.29 \\
\hline GDP2 & 4.07 & 2.18 & 2.19 & 13.57 & 14.66 & 19.13 & 11.26 \\
\hline & 0.40 & 0.70 & 0.70 & 0.01 & 0.01 & 0.00 & 0.02 \\
\hline GDP3 & 6.44 & 1.99 & 12.12 & 4.14 & 7.75 & 2.93 & 3.78 \\
\hline & 0.17 & 0.74 & 0.02 & 0.39 & 0.10 & 0.57 & 0.44 \\
\hline
\end{tabular}


Table 4 presents Granger Causality statistics. Panel A represents the specification that growth in transportation does not Granger Cause growth in GDP. Panel B represents the specification that GDP growth does not Granger Causes the inputs. $\mathrm{C}^{2}$ statistics and their probability are presented. Rejection in Panel A implies that transportation Granger Causes GDP growth. Rejection in Panel B implies that GDP Granger Causes transportation growth.

\section{Policy Implications}

Comparing the costs versus the benefits of transportation's effects on the Chinese economy is difficult, but imperative. The Chinese government does not report transportation budgetary items or expenditures by province (or city), which is the focus of the paper; instead, they report only aggregate annual infrastructure spending. The GMM estimates in column I of Table 4 show rail coefficient is 10.7 and road is 7.2 . Since the estimates are multiplied by 100 for presentation, a $1 \%$ increase in rail (roads) leads to 107 (.072) increases in GDP growth.

Consider the road budget, Table I shows an average growth of $19.5 \%$; table II shows the average growth in turnover is $19.2 \%$ and hence approximately the same. Thus, if the authorities increase the rail budget $20 \%$ annually (close to the historical average), it will cost 806 billion RMB (4030*.2), this will generate an increase of GDP of .20*.072*82428 (GDP in billions for 2017) $=1187$ billion RMB. The benefit of 1191 billion RMB is 1.67 times greater than the cost of 806 billion RMB. To estimate rail's impact, we multiply the GMM estimate of .107 times the ratio of increase in transportation in our sample of .069 divided by annual spending increases of .128 (which equals 0.53 ). Then consider if the authorities increase the budget by the historical annual average of $12.8 \%$, it will cost $59(.128 * 461)$ billion RMB. This compares to $.128^{*} .107^{*} .53^{*} 82428 \mathrm{RMB}$, which equals 598 billion RMB. This is ten times the expenditures. Thus, in term of 'bang for buck', rail outperforms other methods of transport. Note, we do not consider the cost versus the benefits for air, water and HSR, since the GMM estimates in Table 4 are typically insignificant.

\section{Conclusion}

We examine the relationship between growth in transportation and economic output across China's 31 provinces from 2005-2014. GMM estimates demonstrate relatively large and significant effects of road and rail on provincial output growth. Rail's impact particularly is robust across time and econometric specifications and has a large effect on agriculture and manufacturing. GMM methods document little sizeable effects of air, HSR and water on output. HSR's impact is insignificant in the eastern region, and its effect considerably less than conventional rail. Impulse 
response functions document the importance of both rail and roads to future output, and the lack of sizeable effects for air, HSR and water infrastructure growth.

The government's ongoing efforts hence to promote both HSR and air by large infrastructure spending thus maybe misplaced. Results also demonstrate that infrastructure's impact on service growth is lower than manufacturing, and the impact of human capital is more important. Budget spending for fixed investment however for building roads outweighs building schools by more than three to one. Thus, as China begins its transition from a manufacturing economy to more serviceoriented economy, its priorities toward fixed investment should also experience transition.

\section{References}

Ansar, A., Flyvbjerg, B., Budzier, A. \& Lunn, D. (2016) Does Infrastructure investment lead to economic growth or economic fragility? Evidence from China. Oxford Review of Economic Policy, 32(3), 360-390.

Arellano, M. \& Bover, O. (1995) Another look at the instrumental variable estimation of error component models. Journal of Econometrics, 68 (1), 29-51.

Aschauer, D.A. (1989) Is public expenditure productive? JME 23, 177-200.

Banerjee, A., Duflo, E. \& Qian, N. (2012) On the Road: Access to Transportation Infrastructure and Economic Growth in China. No. w17897. NBER.

Bernanke, B, Boivin, J. \& Eliasz, P. (2005) Measuring the Effects of Monetary Policy: A FactorAugmented Vector Autoregressive (FAVAR) Approach. QJE, 120(1), 387-422.

Chatman, D. G. \& Noland, R. B. (2011) Do public transport improvements increase agglomeration economies? A review of literature and an agenda for research. Transport Reviews, 31(6), 725-742.

Chen, C.L \& Vickerman, R. (2016) Can transport infrastructure change regions' economic fortunes? Some evidence from Europe and China. Journal of Regional Studies, 51 (1), 144-160.

Chen, Z., Xue, J., Rose, A. \& Haynes, K. (2016). The impact of high-speed rail investment on economic and environmental change in China: A dynamic CGE analysis. Transportation Research Part A: Policy and Practice, 92, 232-245.

China Statistical Yearbook (2005-2014), National Bureau of Statistics.

China.org (2014) Nearly 80\% of small airports face huge losses. [Online] Available from: www. china.org.cn/business/2014-10/31/content_33932295.htm [Accessed 31st August 2019].

Fogel, R. (1962) A Quantitative Approach to the Study of Railroads in American Economic Growth: A Report of Some Preliminary Findings, Journal of Economic History, 22 (2), 163-197.

Fujita, M., Krugman, P. R., \& Venables, A. J. (1999) The spatial economy: Cities, regions and international trade. Cambridge, MA: MIT Press.

Huifeng, H. (2017) The Chinese airports snapping at Hong Konq's heels. South China Morning Post. [Online] Available from: https://www.cnbc.com/2017/06/01/the-chinese-airportssnapping-at-hong-kongs-heels.htm] [Accessed 31st August 2019].

Liu, C. (2016][Online] Available from: https://thenanfang.com/china-to-boost-airportinfrastructure-by-billions 
Li, H., Strauss, J. \& Lui, L. (2018) Do high-speed railways lead to urban economic growth in China? A panel data study of China's cities. The Quarterly Review of Economics and Finance, 69, 70-89.

Mitchell, T. \& Liu, X. (2018) China's high-speed rail and fears of fast track to debt. Financial Times [Online] Available from: https://www.ft.com/content/ca28f58a-955d-11e8-b747fb1e803ee64e [Accessed 31st August 2019].

Modak, S. (2017)How U.S. airports are catering to 'gate huggers'. Conde Nast Traveler [Online] Available from: https://www.cntraveler.com/story/how-us-airports-are-catering-to-gatehuggers [Accessed 31st August 2019].

Munnell, A. H. (1990) Why has productivity growth declined: Productivity and public investment. New England Economic Review, (January/February), 3-22.

National Railway Administration of the People's Republic of China. (n.d.) [Online] Available from: http://www.nra.gov.cn/ [Accessed 31 ${ }^{\text {st }}$ August 2019].

OECD. (2016). Infrastructure investment. [Online] Available from: https://data.oecd.org/ transport/infrastructure-investment.htm [Accessed 31st August 2019].

Sasaki, K., Ohashi, T. \&Ando, A. (1997) High-speed rail transit impact on regional systems: does the Shinkansen contribute to dispersion. The Annals of Regional Science. 31, 77-98.

Tong, T. \& Yu, T. E. (2018) Transportation and economic growth in China: A heterogeneous panel cointegration and causality analysis. Journal of Transport Geography, 73, 120-130.

UIC (Union Inter Des Chemins Fer). (2018) HIGH-SPEED DATABASE \& MAPS. [Online] Available from: https://uic.org/high-speed-database-maps [Accessed 31st August 2019].

Wu, J., Nash, C. \& Wang, D. (2014) Is High Speed Rail an Appropriate Solution to China's Rail Capacity Problems? Journal of Transport Geography, 40, 100-111.

Figure I: Impulse Response Graphs of Real GDP growth to Transportation

Accumulated Response to Generalized One S.D. Innovations \pm 2 S.E.
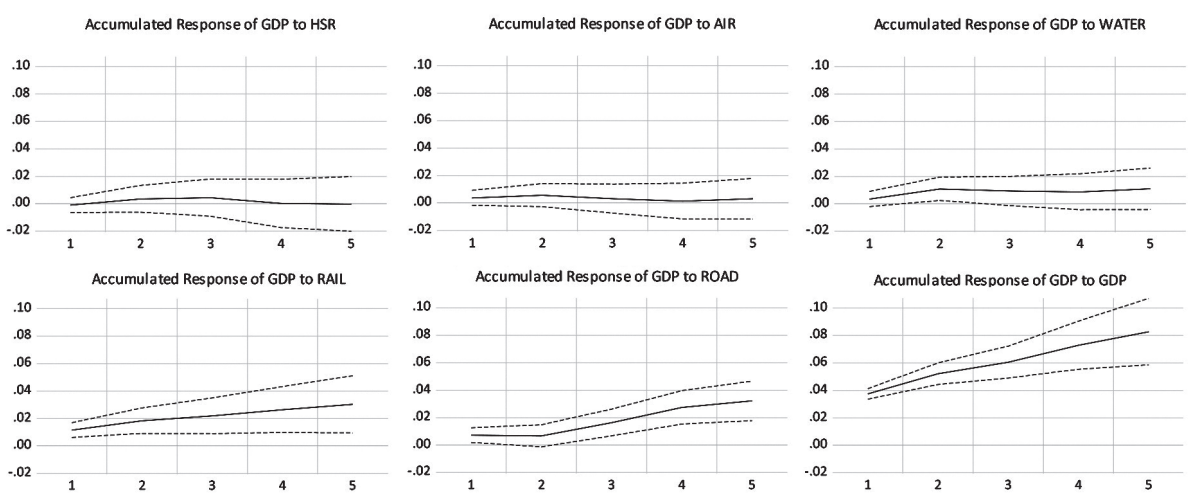
Figure II: Impulse Response Graphs of Transportation to Real GDP

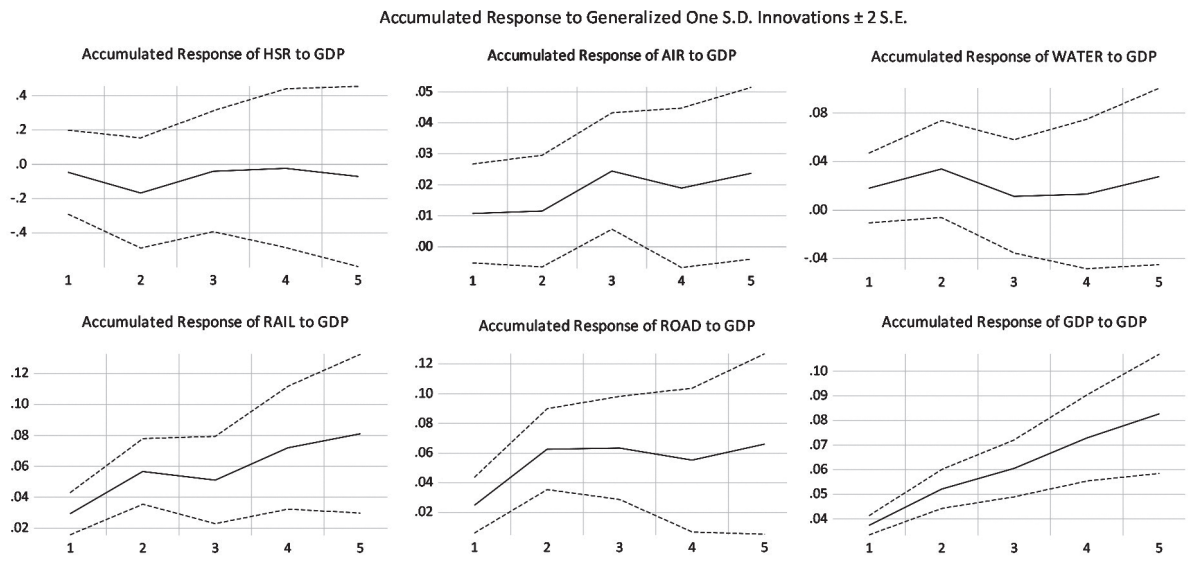

\section{Bio-note}

Dr Jack Strauss has extensive forecasting experience including over four dozen publications using advanced statistical methods in the top journals in Finance, Econometrics and Economics. These include the Journal of Finance, Review of Financial Studies, Review of Finance, Journal of Portfolio Management, Journal of Applied Econometrics, Journal of Forecasting, International Journal of Forecasting, Econometric Reviews, Review of International Economics, Journal of International Money and Finance, Journal of Urban Economics, Journal of Macroeconomics and Economic Letters. He has consulted for the Central Bank of Azerbaijan, Egypt, Indonesia and Ukraine.

Professor Hongchang Li is the Vice Dean of Department of Economics, and an Associate Professor of Transportation Economics and Policy at Beijing Jiaotong University.

Kemei Yu and Xinyu Wu are graduate students in the Department of Economics at Beijing Jiaotong University. 